\title{
₹USGS
}

\section{The Limit of Inundation of the September 29, 2009, Tsunami on Tutuila, American Samoa}

By Bruce E. Jaffe, Guy Gelfenbaum, Mark L. Buckley, Steve Watt, Alex Apotsos, Andrew W. Stevens, and Bruce M. Richmond

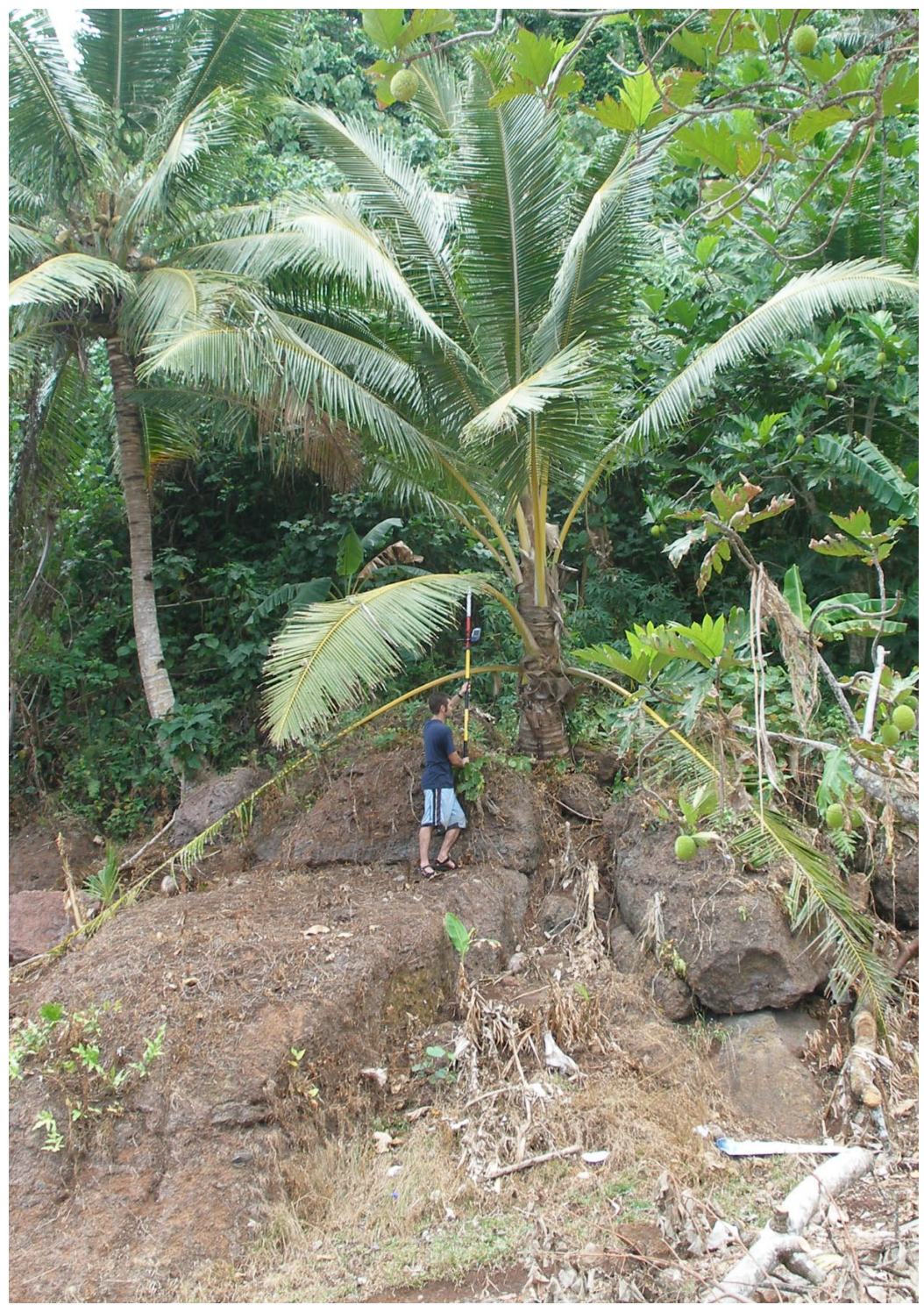

Open-File Report 2010-1018

U.S. Department of the Interior

U.S. Geological Survey 


\section{U.S. Department of the Interior \\ KEN SALAZAR, Secretary}

U.S. Geological Survey
Marcia K. McNutt, Director

U.S. Geological Survey, Reston, Virginia: 2010

For product and ordering information:

World Wide Web: http://www.usgs.gov/pubprod/

Telephone: 1-888-ASK-USGS

For more information on the USGS-the Federal source for science about the Earth, its natural and living resources, natural hazards, and the environment: World Wide Web: http://www.usgs.gov/

Telephone: 1-888-ASK-USGS

Suggested citation:

Jaffe, B.E., Gelfenbaum, Guy, Buckley, M.L., Watt, Steve, Apotsos, Alex, Stevens, A.W., and Richmond, B.M., 2010, The limit of inundation of the September 29, 2009, tsunami on Tutuila, American Samoa: U.S. Geological Survey Open-File Report 2010-1018, 27 p. [http://pubs.usgs.gov/of/2010/1018/.

Any use of trade, product, or firm names is for descriptive purposes only and does not imply endorsement by the U.S. Government.

Although this report is in the public domain, permission must be secured from the individual copyright owners to reproduce any copyrighted material contained within this report. 


\section{Contents}

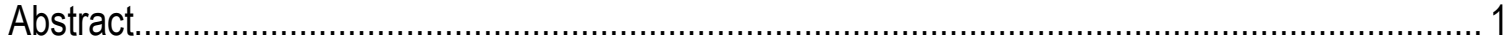

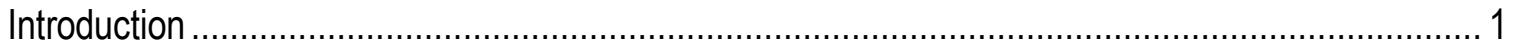

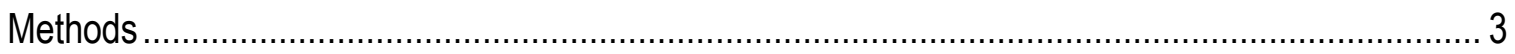

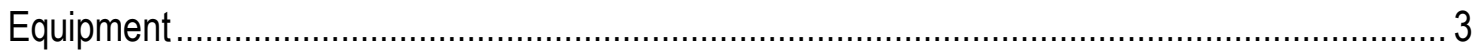

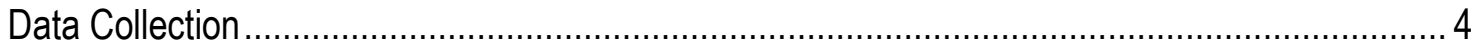

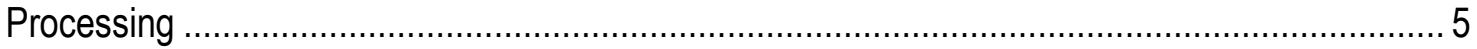

Uncertainty in Location of the Inundation Line ................................................................

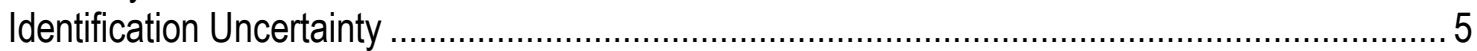

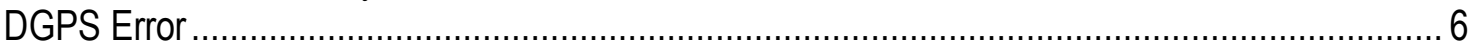

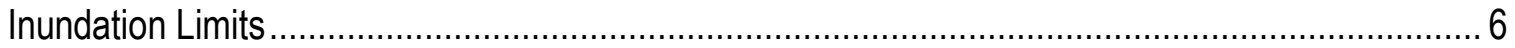

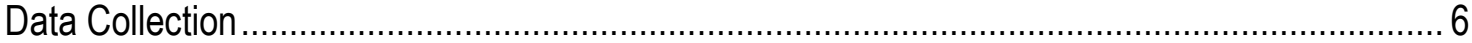

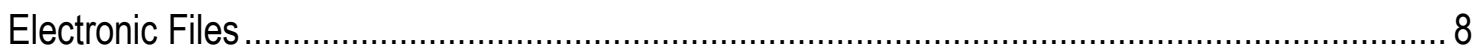

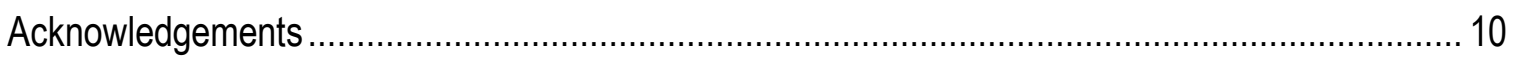

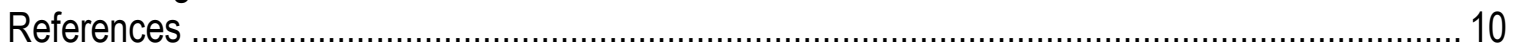

Appendix

\section{Figures}

1. Location of Tutuila, American Samoa ………………………..................................................... 3

2. Surveying limit of inundation using antenna fixed to pole that collected data for DGPS positioning.

3. Locations on Tutuila, American Samoa where inundation limits of the September 29, 2009, tsunami were measured ...........................................................................................

A1. Limit of inundation of the September 29, 2009, tsunami at Poloa, American Samoa............... 13

A2. Limit of tsunami inundation of the September 29, 2009, tsunami at Maloata, American

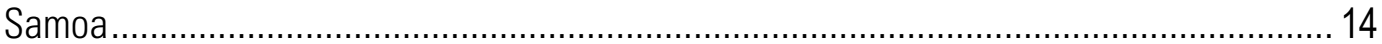

A3. Limit of tsunami inundation of the September 29, 2009, tsunami at Fagamalo, American

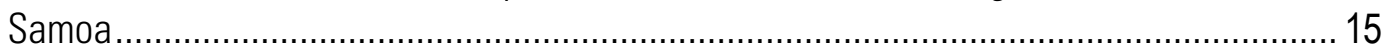

A4. Limit of inundation of the September 29, 2009, tsunami at Massacre Bay, American Samoa .. 16

A5. Limit of inundation of the September 29, 2009, tsunami at Fagafue Bay, American Samoa .... 17

A6. Limit of inundation of the September 29, 2009, tsunami at Fagasa Bay, American Samoa.

The villages of Fagalea, Fangasa, and Fagatele are within the Bay ................................ 18

A7. Limit of inundation of the September 29, 2009, tsunami at Afono, American Samoa ............... 19

A8. Limit of inundation of the September 29, 2009, tsunami at Masefau, American Samoa .......... 20

A9. Limit of inundation of the September 29, 2009, tsunami at Tula, American Samoa.................21

A10. Limit of inundation of the September 29, 2009, tsunami at Fagaitua, American Samoa ......... 22

A11. Limit of inundation of the September 29, 2009, tsunami at Alega, American Samoa ............ 23

A12. Limit of inundation of the September 29, 2009 tsunami at Vailoatai, American Samoa ......... 24

A13. Limit of inundation of the September 29, 2009, tsunami at Auma and Leone, American 
A14. Limit of inundation of the September 29, 2009, tsunami at Asili, American Samoa .............. 26

A15. Limit of inundation of the September 29, 2009, tsunami at Afao, American Samoa.............. 27

\section{Tables}

1. Sites on Tutuila, American Samoa where inundation limits for the September 29, 2009, tsunami were measured.

2. Example of information on inundation from the September 29, 2009, tsunami contained in electronic files. 


\title{
The Limit of Inundation of the September 29, 2009 Tsunami on Tutuila, American Samoa
}

By Bruce E. Jaffe, Guy Gelfenbaum, Mark Buckley, Steve Watt, Alex Apotsos, Andrew W. Stevens, and Bruce M. Richmond

\begin{abstract}
U.S. Geological Survey scientists investigated the coastal impacts of the September 29, 2009, South Pacific tsunami in Tutuila, American Samoa in October and November 2009, including mapping the alongshore variation in the limit of inundation. Knowing the inundation limit is useful for planning safer coastal development and evacuation routes for future tsunamis and for improving models of tsunami hazards. This report presents field data documenting the limit of inundation at 18 sites around Tutuila collected in the weeks following the tsunami using Differential GPS (DGPS). In total, 15,703 points along inundation lines were mapped. Estimates of DGPS error and uncertainty in interpretation of the inundation line are provided as electronic files that accompany this report.
\end{abstract}

\section{Introduction}

On September 29, 2009, a magnitude-8.1 submarine earthquake occurred at 6:48 a.m. Samoa Standard Time approximately $190 \mathrm{~km}$ (120 mi) southwest of Samoa (U.S. Geological Survey 2009a). The earthquake triggered a tsunami that caused 184 deaths, 7 missing and presumed dead, and widespread damage in Samoa, American Samoa, and Tonga (United Nations Office for the Coordination of Humanitarian Affairs, 2009; Federal Emergency Management Agency, 2009). This is the first tsunami to cause casualties on U.S. soil in more than 30 years.

Scientists from around the world quickly mobilized to document the impact of the tsunami before ephemeral data, such as the landward extent of tsunami flooding or inundation limit, were lost to recovery activity and natural processes. The tsunami reached elevations greater than $12 \mathrm{~m}$ above sea level and flooded regions more than 600 $\mathrm{m}$ inland. Although this report focuses on the measurement of the inundation limit, measurements of the wave heights, flow depths, sediment deposits, and other physical and ecological impacts were also recorded, and all the data collected will be used to improve the understanding of tsunamis in the Pacific and elsewhere in the world.

Rapid response teams of U.S. Geological Survey (USGS) scientists traveled to Tutuila, American Samoa from October 4-22 and November 5-12, 2009, to collect data (fig. 1). 
During the first field survey a variety of water-level and other field measurements were collected to document impacts of the tsunami (U.S. Geological Survey 2009a). The second survey focused on the need to better define the alongshore variation in the limit of tsunami inundation because the primary strategy of previous international survey teams was to collect data along shore-normal transects or at individual points at a large number of locations before the physical evidence of water levels degraded. Except for an international team of scientists from Japan, the United States, and American Samoa (Koshimura and others, 2009a,b) that walked the limit of inundation at Amanave and the western end of Pago Pago harbor, this effort by the USGS was the only attempt to collect field measurements of the continuous alongshore variation of the limit of tsunami inundation around Tutuila. The inundation line is useful for planning safer coastal development and evacuation routes for future tsunamis and for improving models of tsunami hazards.

This report presents field measurements of the inundation limit from the September 29, 2009, tsunami collected by USGS scientists on Tutuila, American Samoa. The methods of data collection and associated errors are discussed to allow users to critically evaluate the information and determine how best to apply these data for their purposes. Maps showing the limit of inundation overlain on satellite images, as well as GIS, spreadsheet, and text files are included to facilitate the use of these data. 


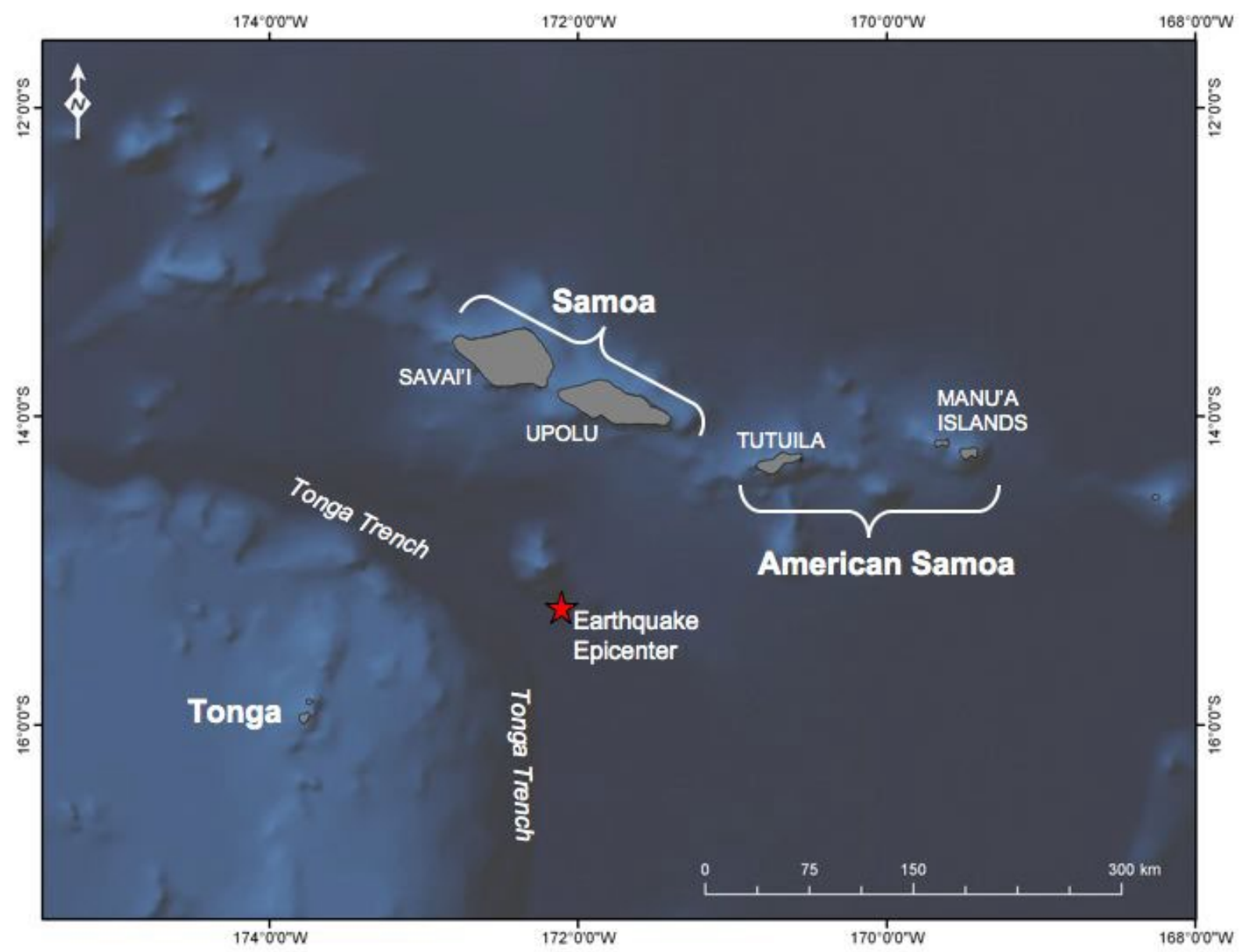

Figure 1. Location of Tutuila, American Samoa. The epicenter of September 29, 2009 earthquake, which is in the region where the tsunami was generated, is also shown.

\section{Methods}

\section{Equipment}

The inundation limit was mapped using three Differential GPS-enabled (DGPS)

Magellan ProMark 3 L1 receivers. The units were mounted to $\sim 1.9$-m-long survey poles and equipped with NAP 100 antennas fixed to the top of the pole (fig. 2). 


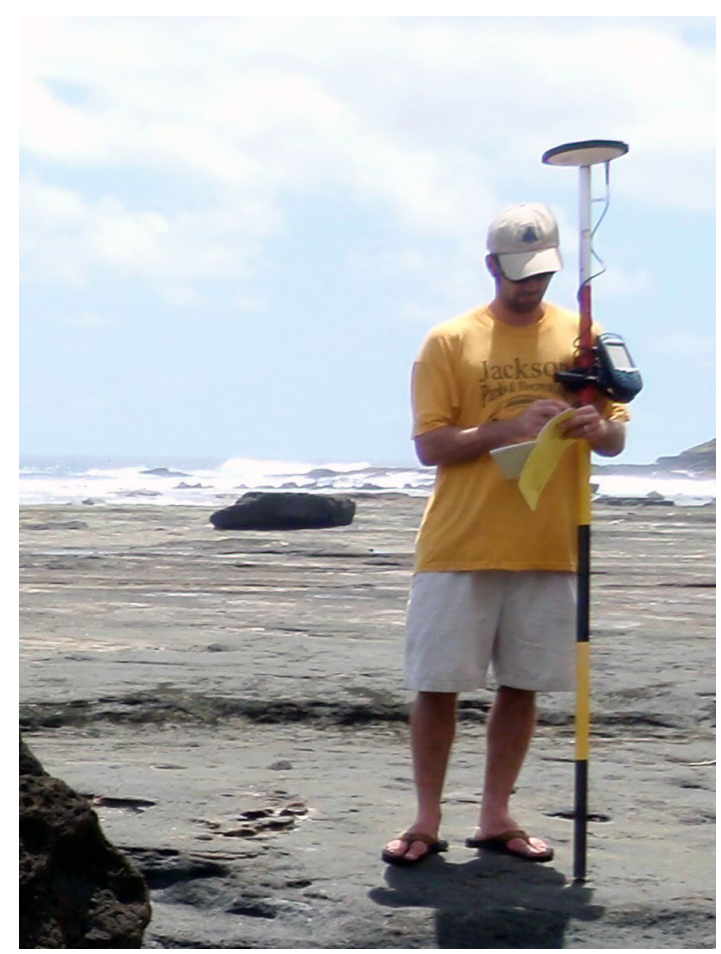

Figure 2. Surveying limit of inundation using antenna fixed to pole that collected data for DGPS positioning.

\section{Data Collection}

Inundation lines were walked during two survey periods, October 9-17 and November 612,2009 . The interpreted location of the inundation line was based on the remaining physical evidence of tsunami inundation and, whenever possible, interviews with local residents. Typically, two scientists worked together to confirm interpretations.

Identification of the inundation limit involves interpreting the division between adjacent areas that show evidence of inundation and areas that do not. Along this division a concentration of debris, often called a debris or wrack line, may be present. Indicators of tsunami inundation include debris, bent or snapped vegetation, sand or boulder deposits, erosion, damage to structures or their contents, water marks on structures, and salt-burnt vegetation.

The interpretation of the limit of tsunami inundation from physical evidence was augmented by interviews with local residents. Most interviewees were not present in the villages during the tsunami, but were able to assist in the identification of the limit of inundation based on their recollections and interpretations of remaining debris and damage to vegetation and property from the tsunami. In some cases during the later surveys the physical evidence had degraded to a point where eyewitness interviews were the primary source of information. Care was taken, particularly during the November surveys, to assess and document the uncertainty in the interpretation of the location of the inundation limit. 


\section{Processing}

The National Geodetic Survey (NGS) Continuously Operating Reference Station (CORS) at site ASPA in Pago Pago (National Geodetic Survey [2009]) was used as a base station to differentially correct the ProMark 3 GPS rover data. The differential corrections were post-processed using either Magellan's GNSS Solutions 3.10.07 (Magellan, 2008) or Novatel's GrafNav 8.2 software packages (Novatel, 2009). The DGPS inundation line positions were imported and edited in a GIS. The results are displayed on 1-m resolution satellite images (U.S. Department of Agriculture, [2010]) taken in 2005 before the tsunami.

\section{Uncertainty in Location of the Inundation Line}

The locations of the inundation limit presented in this report are a best estimate. For many purposes, these locations will suffice. However, for other applications it will be necessary to assess the uncertainty in the reported locations. Uncertainty in the estimated locations derives from two primary sources: (1) the field interpretation of the location of the inundation limit and (2) DGPS error.

\section{Identification Uncertainty}

Inundation data were collected from 10 to 44 days after the tsunami. During this time span, clean up was ongoing, and natural processes were acting to degrade or remove the evidence of tsunami inundation. In populated areas evidence was removed or altered during the rapid clean up immediately following the tsunami. Post-tsunami rain and river flooding also removed and altered physical evidence in many areas. These processes are not spatially uniform and introduce a variable uncertainty into the data collected. To account for the introduction of this nonuniform uncertainty, photos and careful notes were taken, and a continuous estimate of the uncertainty was made.

A value of $<2 \mathrm{~m},<5 \mathrm{~m},<10 \mathrm{~m}$, or $<20 \mathrm{~m}$ was assigned to each data point as the uncertainty in the interpretation of the location of the limit of inundation. Although an attempt was made to standardize the estimates of how close the line we walked was to the actual inundation line, such standardization was not possible because not all scientists were present for each survey. The uncertainties reported in the files accompanying this report, therefore, are intrinsically subjective.

Guiding principles for assigning horizontal uncertainty in the interpretation of the limit of inundation are that uncertainties are lower for (1) fresher evidence (earlier surveys), (2) steeper slopes, (3) more debris-rich environments, and (4) where an eyewitness accompanied the survey team to point out the limit of inundation. Uncertainty in the location of the inundation line was typically greater landward of the reported position because evidence was interpreted conservatively and inland terrain was difficult to navigate in places (for example, steep vegetated terrain). The uncertainty is also not always symmetric, with locations where there was larger uncertainty landward of the reported location because evidence was interpreted conservatively and inland terrain was difficult to navigate in places (for example, steep vegetated terrain). Often, but not always, the uncertainty in interpreting the location of the limit of inundation was greater than the DGPS error. 


\section{DGPS Error}

Various factors affect the error of a DGPS position including the number and geometry of available satellites, ionospheric interactions, multipath errors, density of vegetation, and topography. As a result the accuracy for DGPS points varies. Points along inundation lines mapped in areas open to the sky with good satellite coverage typically have lower DGPS error than those collected in steep valleys or under a canopy of dense vegetation.

The processing programs a statistically derived error estimate for each DGPS measurement. The error estimate is associated with a confidence level that gives the probability that the true value of the measurement falls within the range generated by subtracting and adding the error estimate to the measured value. The 95-percent confidence level for the horizontal location is reported in the accompanying files. For example, a measurement for the location of the inundation limit of 50.5 meters from shore that has an error estimate of 1.1 meters at the 95-percent confidence level has a 95percent probability that the true value is between 49.4 and 51.6 meters from shore (Magellan, 2008). The software documentation does not provide information for the algorithms used to calculate this estimate, and it was therefore impossible to determine the quality of the estimate.

\section{Inundation Limits}

The aim of data collection was to document the large-scale variability in tsunami inundation on the island of Tutuila, American Samoa. These data should not be used to determine whether individual structures were inundated or damaged by the tsunami.

\section{Data Collection}

Inundation data were collected at 18 sites around Tutuila (fig. 3, table 1). A total of 15,703 inundation limit points were collected. Estimates of the maximum inundation for each village or embayment from measurements in a GIS are reported in table 1. Only the location of the limit of inundation, not the DGPS error or interpretation uncertainty, are shown in figures A1-A15 in the appendix. The error and location uncertainty for each point are included in the electronic files accompanying this report. 


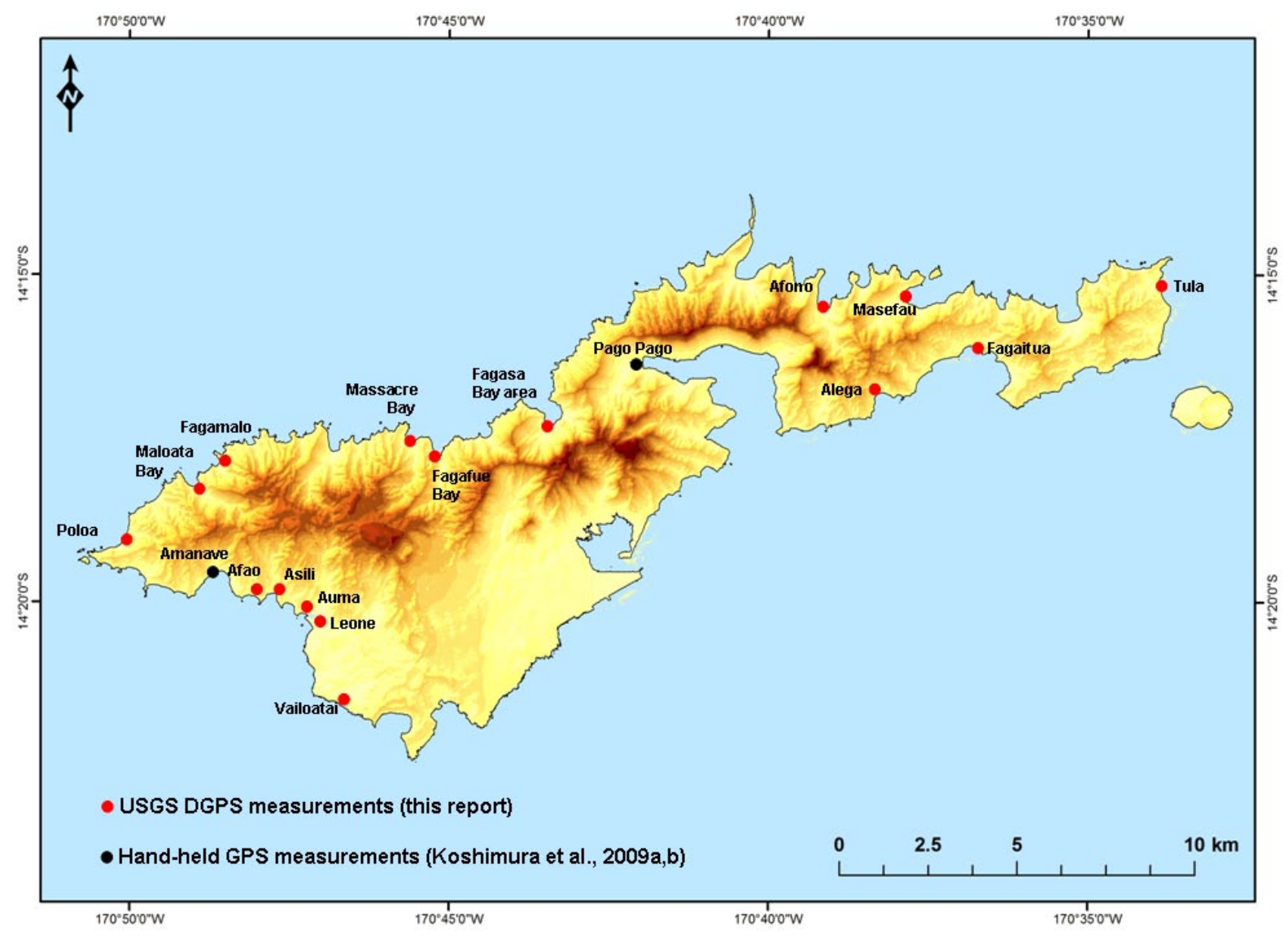

Figure 3. Locations on Tutuila, American Samoa where inundation limits of the September 29, 2009, tsunami were measured. Koshimura and others $(2009 a, b)$ measurement locations shown for reference only. 
Table 1. Sites on Tutuila, American Samoa where inundation limits for the September 29, 2009, tsunami were measured.

[Sites are ordered clockwise starting at Poloa on the northwest coast of Tutuila, American Samoa. Estimates of maximum inundation are approximate.]

\begin{tabular}{||c|c|c||}
\hline Location & Date of Survey in 2009 & Maximum Inundation (m) \\
\hline Poloa & October 9, November 6 & 120 \\
\hline Maloata & October 12 & 160 \\
\hline Fagamalo & October 9 & 110 \\
\hline Massacre Bay & October 14 15 & 80 \\
\hline Fagafue Bay & October 15 & 230 \\
\hline Fagatele & November 9 & 200 \\
\hline Fagasa & November 9 and 11 & 110 \\
\hline Fagalea & November 11 & 170 \\
\hline Afono & November 11 & 190 \\
\hline Masefau & November 12 & 290 \\
\hline Tula & October 19 & 260 \\
\hline Fagaitua & November 12 & 150 \\
\hline Alega & November 7 & 80 \\
\hline Vailoatai & October 17 & 180 \\
\hline Leone & October 17, November 7 and 9 & 620 \\
\hline Auma & November 6 & 500 \\
\hline Asili & October 12, November 6 & 260 \\
\hline Afao & November 6 & 130 \\
\hline \multicolumn{2}{|c|}{} \\
\hline
\end{tabular}

\section{Electronic Files}

UTM coordinates (WGS 1984 UTM Zone 2S) of the inundation limit, as well as DGPS and interpretation uncertainty, are provided in three file types: (1) a comma-delimited text file, (2) a Microsoft Excel spreadsheet, and (3) an ESRI shapefile. An example of the information contained in the electronic files is shown in table 2. Satellite information is $\mathrm{SV}$, the number of satellites, and PDOP, a measure of the precision based on satellite geometry. The DGPS 95-percent confidence level for horizontal positioning (H_95) and whether a solution is fixed (vector integer ambiguities determined) or floating (vector integer ambiguities undetermined) are given. The interpretation uncertainty, Interp_ERR (m), has values of $<2 \mathrm{~m},<5 \mathrm{~m},<10 \mathrm{~m}$, and $<20 \mathrm{~m}$. Also included are the types of evidence ( $1=$ physical, $2=$ interviews, $3=$ both) used to determine the limit of inundation (see Data Collection above), and the date of the survey. Metadata is included in the ESRI shapefile and as a stand-alone text file. 
Table 2. Example of information on inundation from the September 29, 2009, tsunami contained in electronic files.

\begin{tabular}{|c|c|c|c|c|c|c|c|c|c|c|c|}
\hline Loc & East_UTM2S & North_UTM2S & Lon & Lat & H_95 (m) & Sol & SV & PDOP & $\begin{array}{c}\text { Interp } \\
\text { ERR } \\
(\mathrm{m})\end{array}$ & Evidence & Survey Date \\
\hline Afao & 521623.30 & 8415516.69 & -170.7994761 & -14.3322674 & 0.14 & Fixed & 7 & 5.1 & 5 & 3 & $11-6-2009$ \\
\hline Afao & 521623.24 & 8415516.64 & -170.7994766 & -14.3322679 & 0.19 & Fixed & 7 & 5.1 & 5 & 3 & $11-6-2009$ \\
\hline Afao & 521623.19 & 8415516.65 & -170.7994771 & -14.3322678 & 0.19 & Fixed & 7 & 5.1 & 5 & 3 & $11-6-2009$ \\
\hline Afao & 521623.09 & 8415517.02 & -170.7994781 & -14.3322645 & 0.21 & Fixed & 7 & 5.1 & 5 & 3 & $11-6-2009$ \\
\hline Afao & 521622.59 & 8415517.97 & -170.7994827 & -14.3322559 & 0.25 & Fixed & 7 & 5.1 & 5 & 3 & $11-6-2009$ \\
\hline Afao & 521621.95 & 8415519.07 & -170.7994886 & -14.3322459 & 0.23 & Fixed & 7 & 5.1 & 5 & 3 & $11-6-2009$ \\
\hline Afao & 521621.46 & 8415520.20 & -170.7994931 & -14.3322357 & 0.24 & Fixed & 6 & 7.6 & 5 & 3 & $11-6-2009$ \\
\hline Afao & 521621.01 & 8415521.43 & -170.7994974 & -14.3322246 & 0.24 & Fixed & 7 & 5.1 & 5 & 3 & $11-6-2009$ \\
\hline Afao & 521620.51 & 8415522.57 & -170.7995020 & -14.3322143 & 0.31 & Fixed & 7 & 5.1 & 5 & 3 & $11-6-2009$ \\
\hline Afao & 521620.01 & 8415523.67 & -170.7995066 & -14.3322044 & 0.30 & Fixed & 7 & 5.1 & 5 & 3 & $11-6-2009$ \\
\hline
\end{tabular}




\section{Acknowledgements}

The USGS Coastal and Marine Geology Program funded this research. We would like to thank Brian Peck (U.S. Department of Agriculture, Natural Resources Conservation Service, American Samoa) for transporting us in his boat and helping map in the areas difficult to reach by land on the north coast of American Samoa. Marie Chan Kau and Sharon Fanolua (American Samoa Community College) were translators and ambassadors for the early surveys. John Goeke (American Samoa Department of Homeland Security), Lauren Wetzell (American Samoa Community College), Don Vargo (American Samoa Community College), and many others in the American Samoa scientific community also helped by providing logistical support. Brenda Jones and Stephen Hammond (USGS) made satellite images available to those responding to the tsunami as soon as possible.

We would like to thank the people of American Samoa who welcomed tsunami response teams into their villages to collect this critical data. We hope that this data, and data collected by others after this tsunami, will decrease loss in future tsunamis in American Samoa and elsewhere.

\section{References}

Federal Emergency Management Agency, 2009, National situation update- Friday October 2, 2009 [accessed on December 30, 2009, at http://www.fema.gov/emergency/reports/2009/nat100209.shtm].

Koshimura, S., Nishimura, Y., Nakamura, Y., Namegaya, Y., Fryer, G.J., Akapo, A., Kong, L.S., and Vargo, D., 2009a, Field survey of the 2009 tsunami in American Samoa: Eos, Transactions of the American Geophysical Union, 90(52), Fall Meeting Supplemental, abstract U23F-07.

Koshimura, S., Nishimura, Y., Nakamura, Y., Namegaya, Y., Fryer, G.J., Akapo, A., Vargo, D., and Kong, L.S., 2009b, Akita University Hydraulic Engineering Lab: Akita University Web site [accessed on December 30, 2009, at http://www.hel.ce.akitau.ac.jp/association/cvl_tsnm/download/21_sympo/koshimura_samoa.pdf] (in Japanese).

Magellan, 2008, GNSS Solutions Reference Manual: 472 p.

National Geodetic Survey, [2009], Continuously Operation Reference Station ASPA: National Geodetic Survey Web site [accessed Decmeber 30, 2009, at http://www.ngs.noaa.gov/cgi-cors/corsage.prl?site=ASPA].

Novatel, 2009, GrafNav/GrafNet User Guide: Publication Number OM-200000105, revision level 5, 309 p.

Promagellan, 2009, Promagellan Web site [accessed December 30, 2009, at www.promagellan.com]. 
United Nations Office for the Coordination of Humanitarian Affairs, 2009: Samoa/Tonga Tsunami Situation Report No. 11, October 22, 2009: United Nations Web site [accessed December 30, 2009, at http://www.reliefweb.int/rw/RWFiles2009.nsf/FilesByRWDocUnidFilename/AZH U-7X42LF-full_report.pdf/SFile/full_report.pdf].

U.S. Department of Agriculture, [2009a], Natural Resources Conservation Service Data Gateway: U.S. Department of Agriculture Web site [accessed January 4, 2010, at http://datagateway.nrcs.usda.gov].

U.S. Geological Survey, 2009, National Earthquake Information Center: U.S. Geological Survey Web site [accessed December 30, 2009, at http://earthquake.usgs.gov/earthquakes/recenteqsww/Quakes/us2009mdbi.php].

U.S. Geological Survey, 2009b, Samoa Tsunami Field Reports: U.S. Geological Survey Web site [accessed January 4, 2010 at http://walrus.wr.usgs.gov/news/samoareports.html]. 


\section{Appendix}

The appendix contains 15 figures with the mapped limit of inundation overlain on 1-m resolution satellite images (U.S. Department of Agriculture, 2010) taken in 2005 before the September 29, 2009, tsunami. The figures are displayed in a clockwise progression starting at Poloa in the northwest of Tutuila, American Samoa. The error and uncertainty for each point are quantified in the electronic files accompanying this report. 


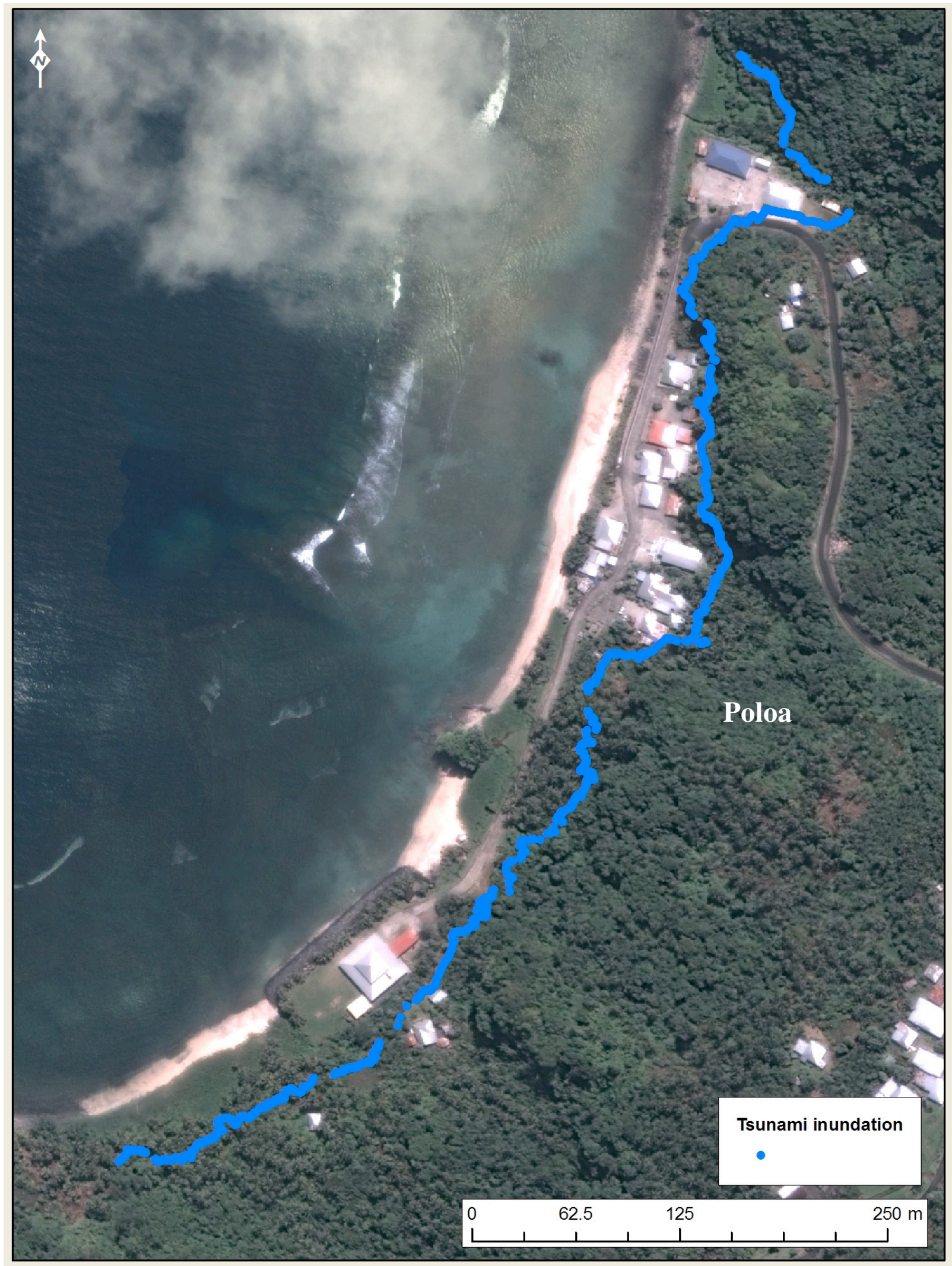

Figure A1. Limit of inundation of the September 29, 2009, tsunami at Poloa, American Samoa. DGPS error and location uncertainty are quantified in the electronic files accompanying this report. 


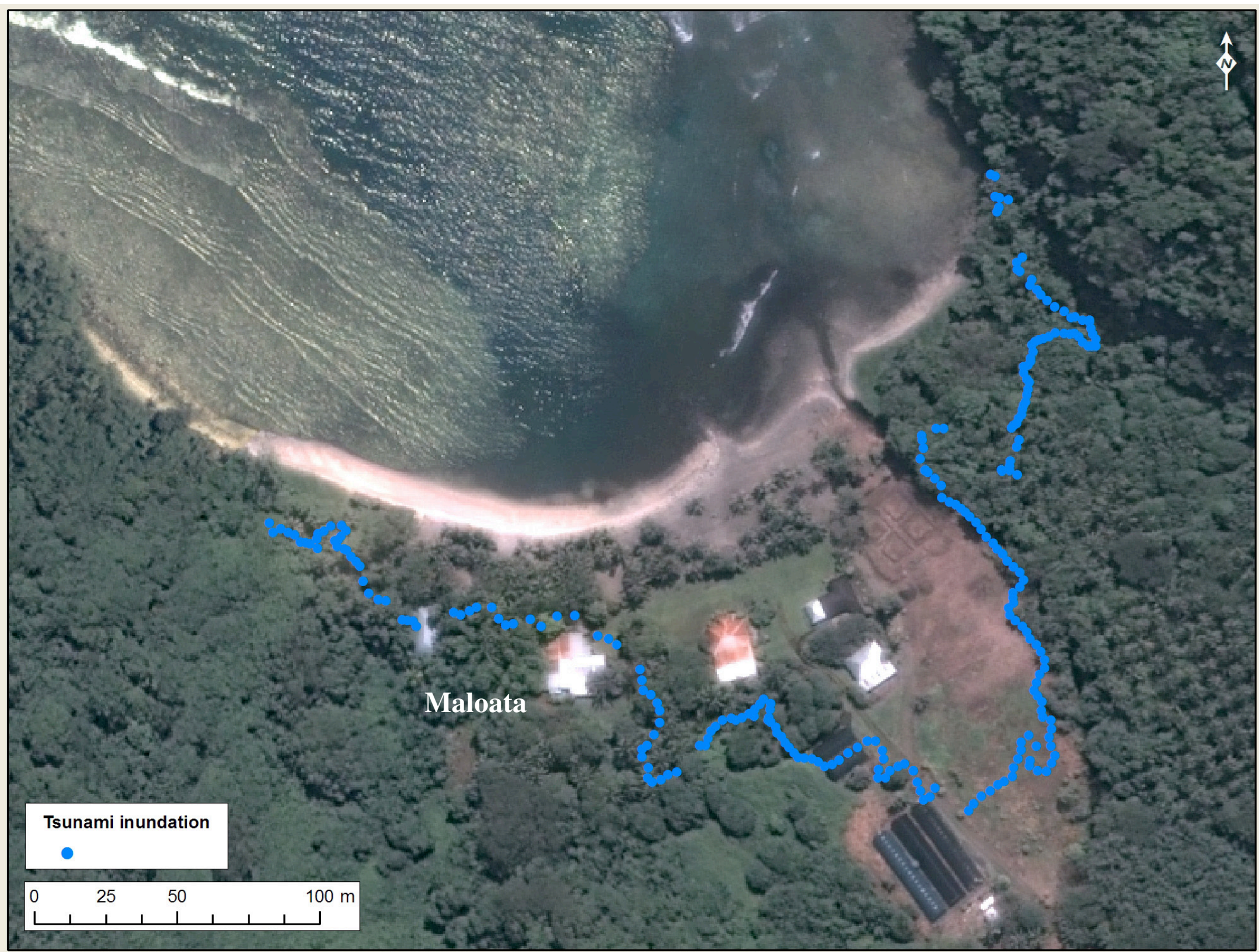

Figure A2. Limit of tsunami inundation of the September 29, 2009, tsunami at Maloata, American Samoa. DGPS error and location uncertainty are quantified in the electronic files accompanying this report. 


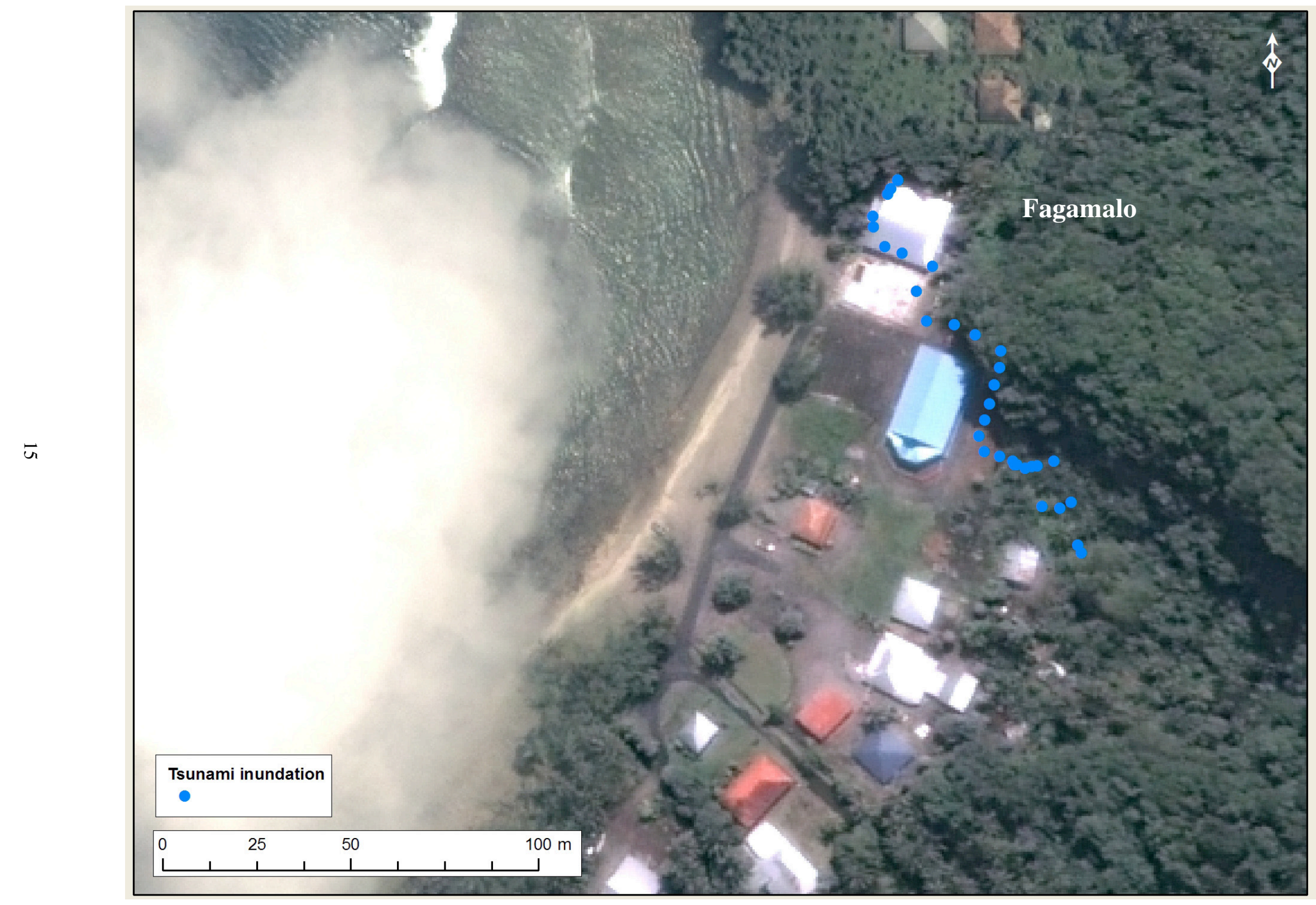

Figure A3. Limit of tsunami inundation of the September 29, 2009, tsunami at Fagamalo, American Samoa. DGPS error and location uncertainty are quantified in the electronic files accompanying this report. 


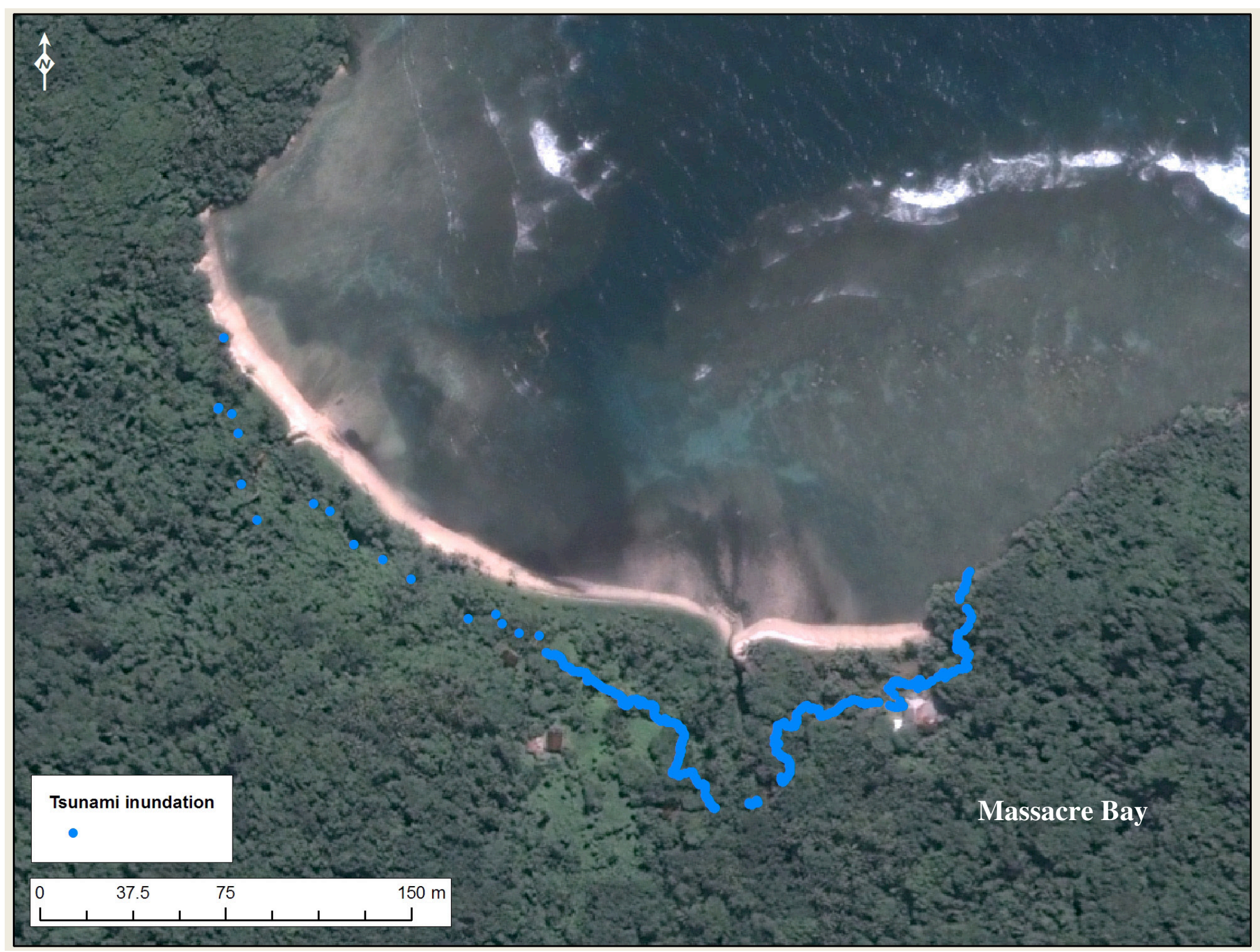

Figure A4. Limit of inundation of the September 29, 2009, tsunami inundation at Massacre Bay, American Samoa. DGPS error and location uncertainty are quantified in the electronic files accompanying this report. 


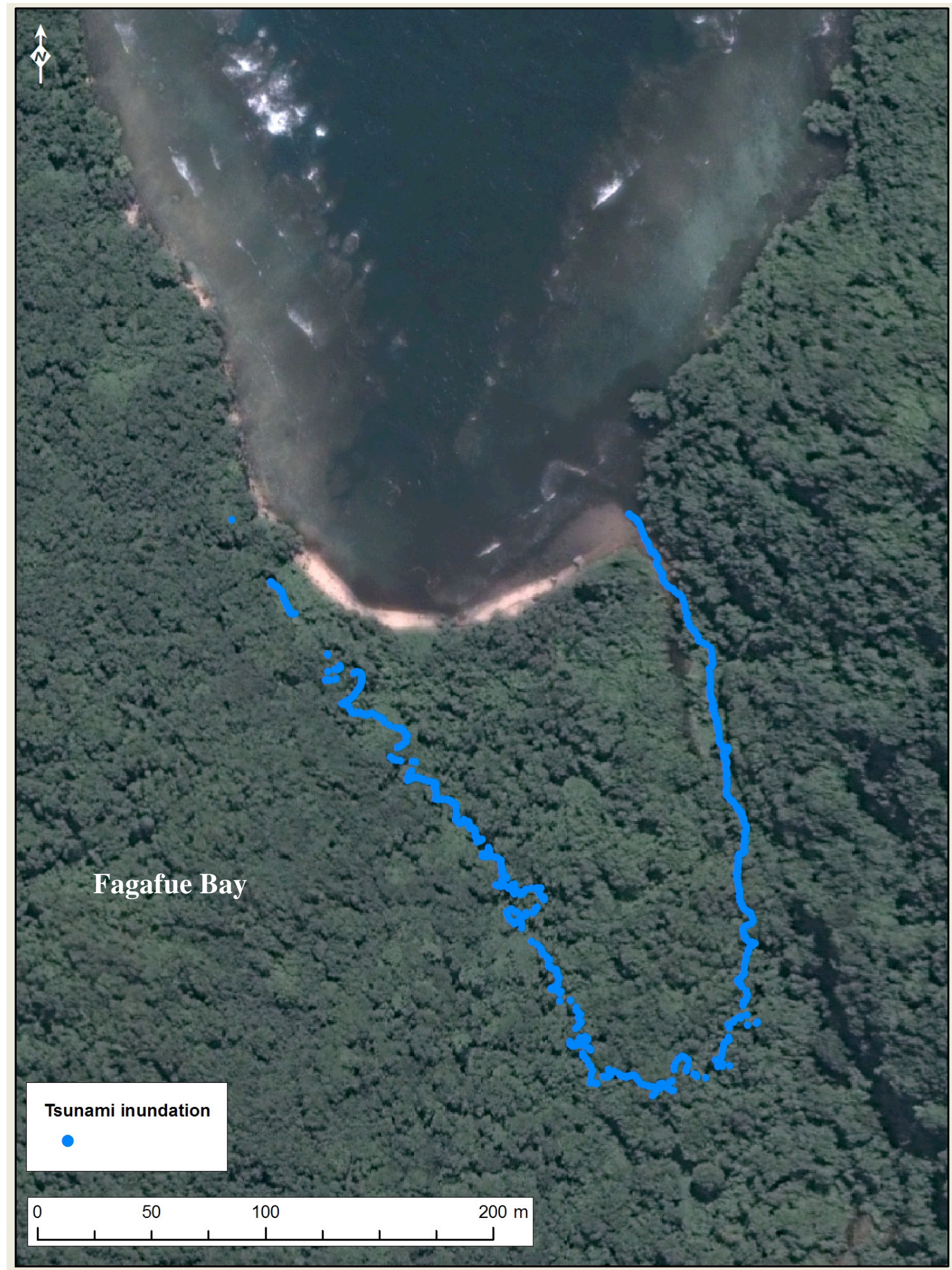

Figure A5. Limit of inundation of the September 29, 2009, tsunami at Fagafue Bay, American Samoa. DGPS error and location uncertainty are quantified in the electronic files accompanying this report. 


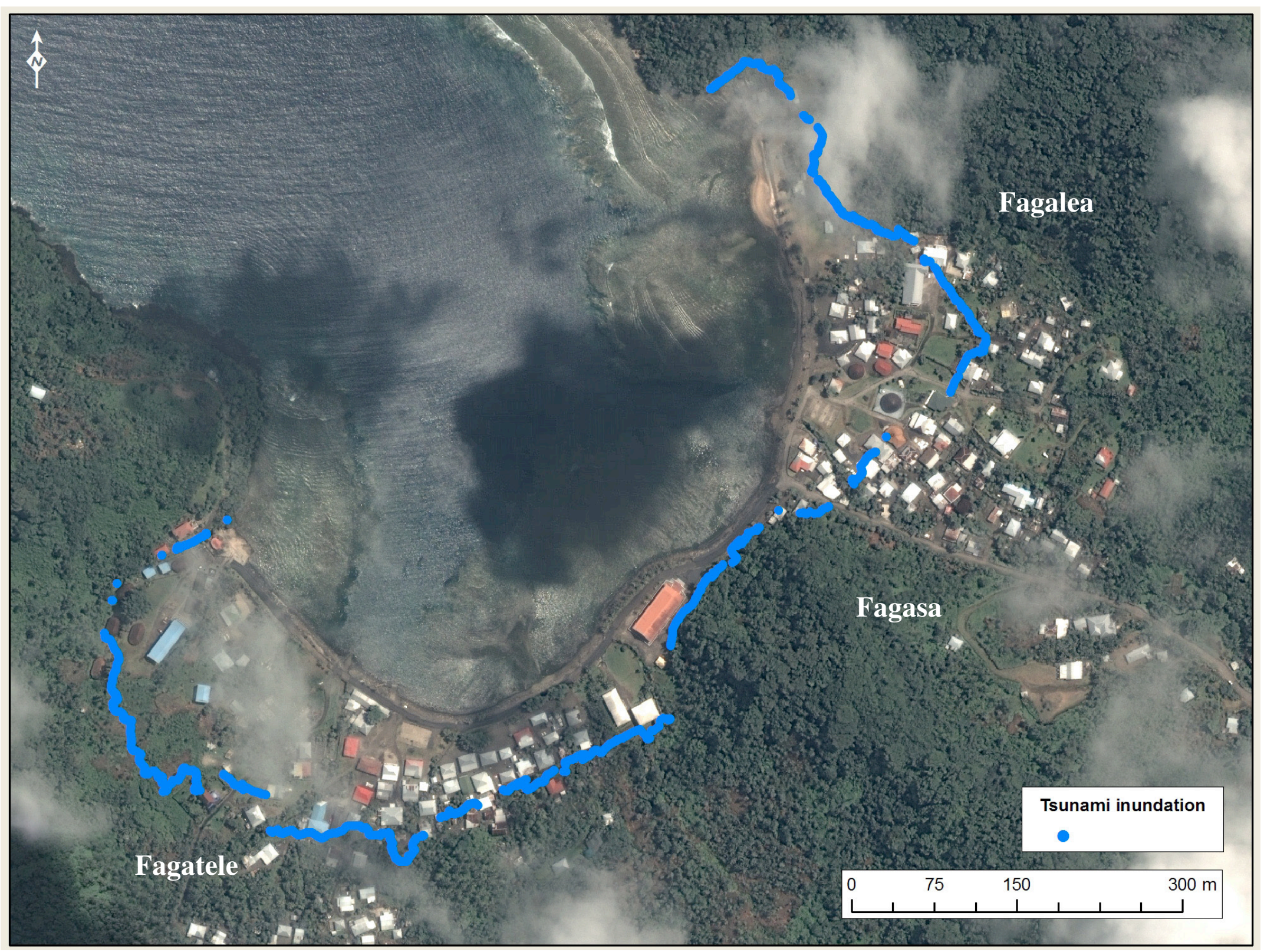

Figure A6. Limit of inundation of the September 29, 2009, tsunami at Fagasa Bay, American Samoa. The villages of Fagalea, Fagasa, and Fagatele are within the Bay. DGPS error and location uncertainty are quantified in the electronic files accompanying this report. 


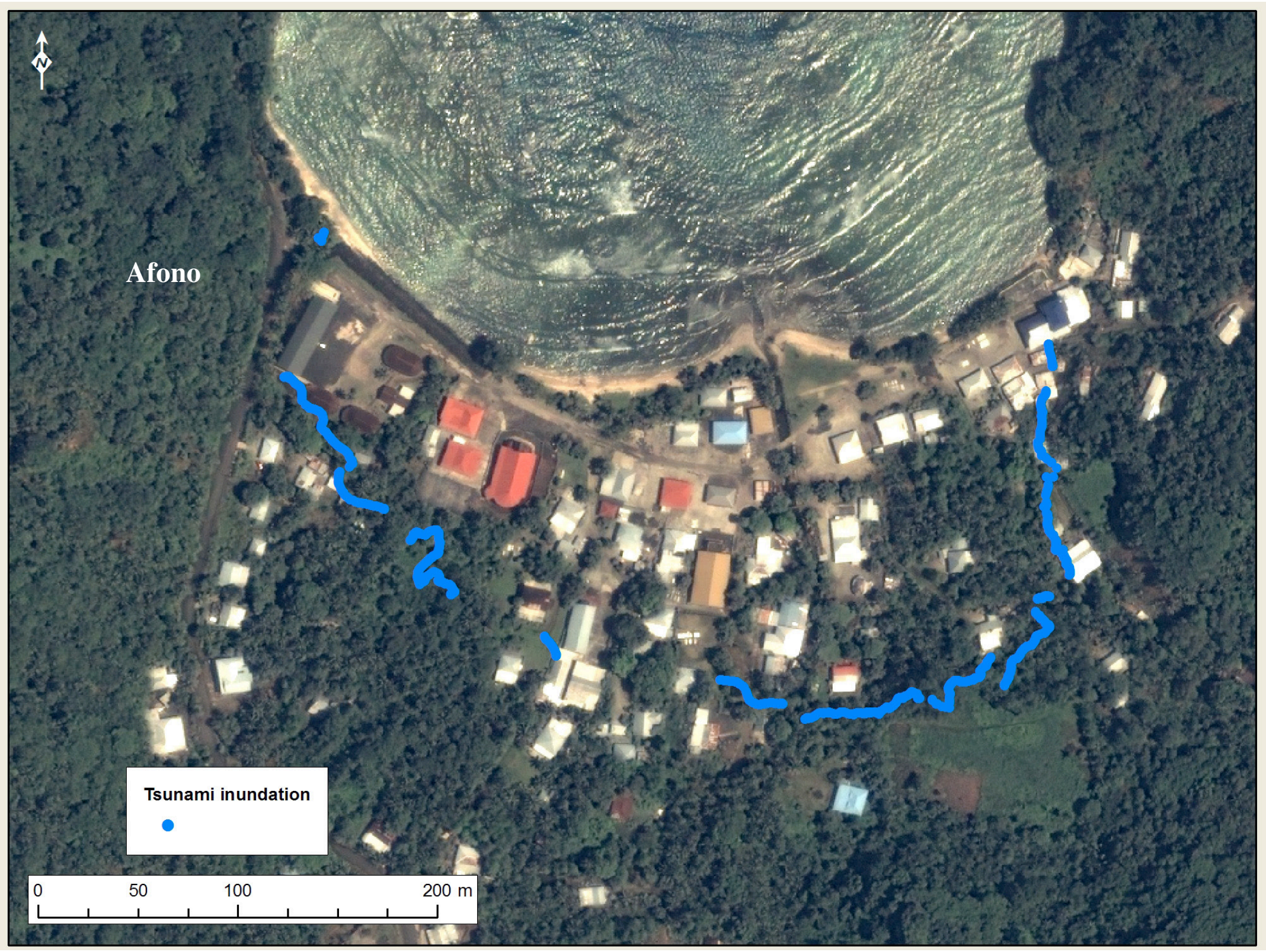

Figure A7. Limit inundation of the September 29, 2009, tsunami at Afono, American Samoa. DGPS error and location uncertainty are quantified in the electronic files accompanying this report. 


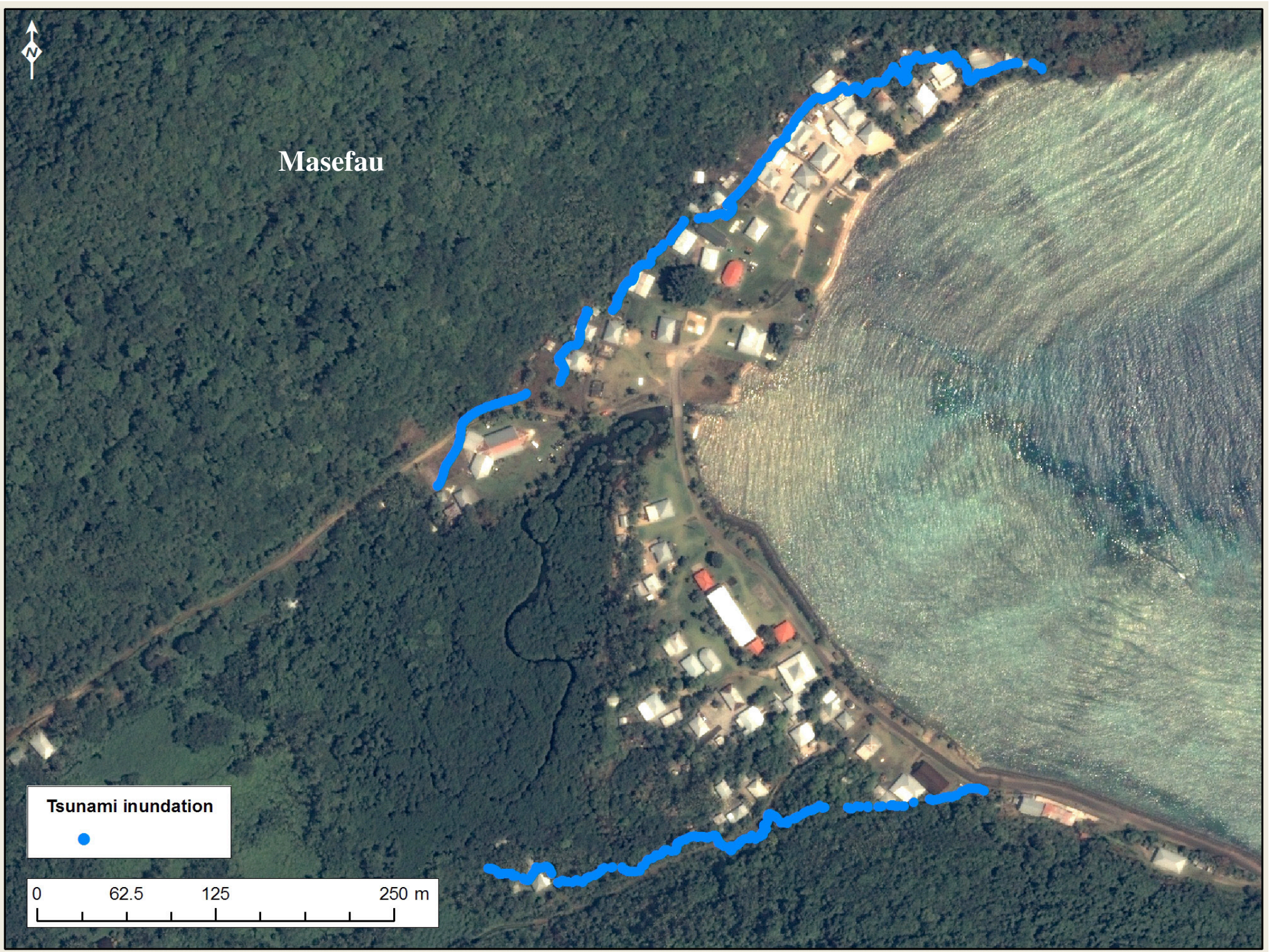

Figure A8. Limit of inundation of the September 29, 2009, tsunami at Masefau, American Samoa. DGPS error and location uncertainty are quantified in the electronic files accompanying this report. 


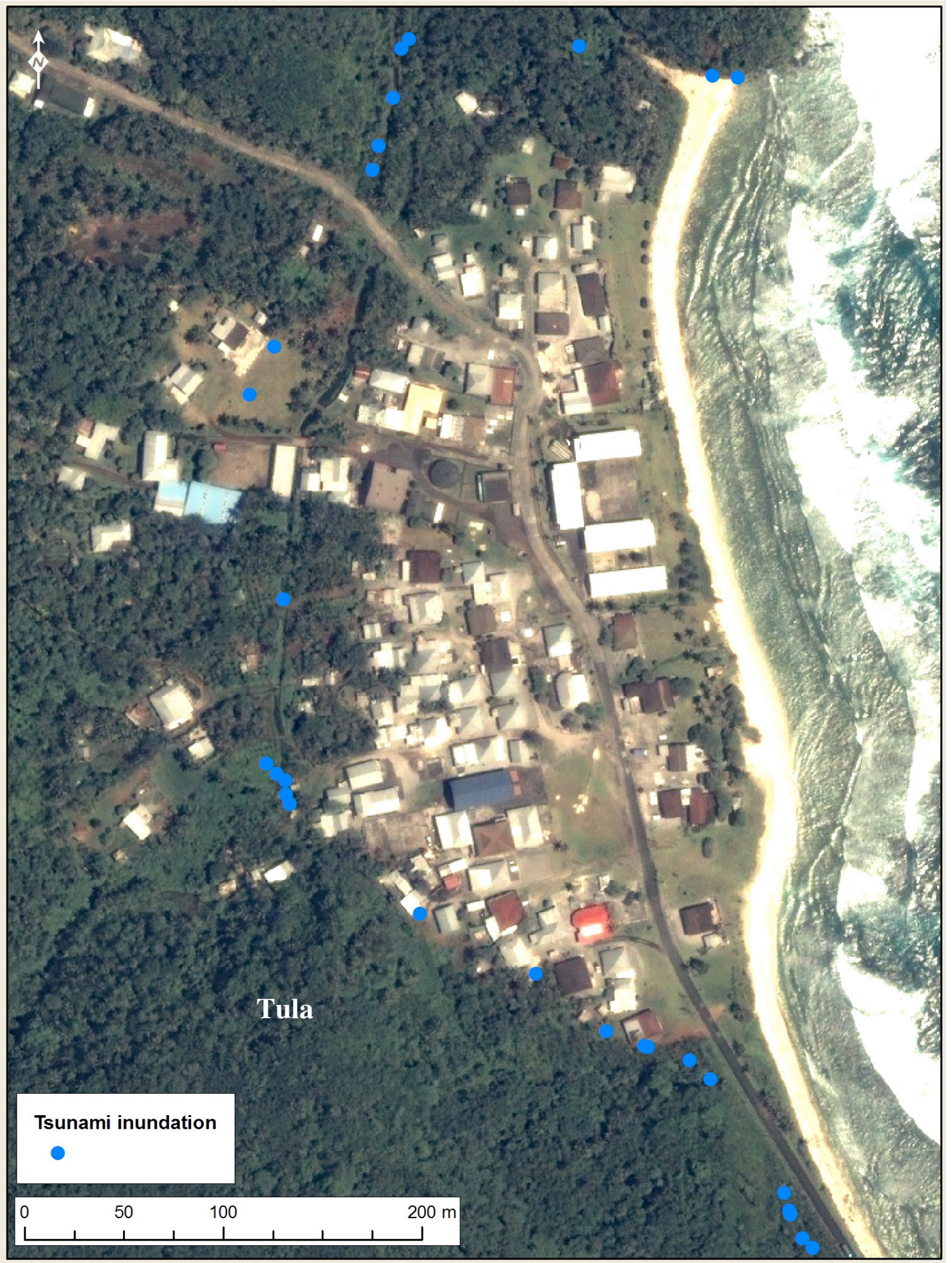

Figure A9. Limit of inundation of the September 29, 2009, tsunami at Tula, American Samoa. DGPS error and location uncertainty are quantified in the electronic files accompanying this report. 


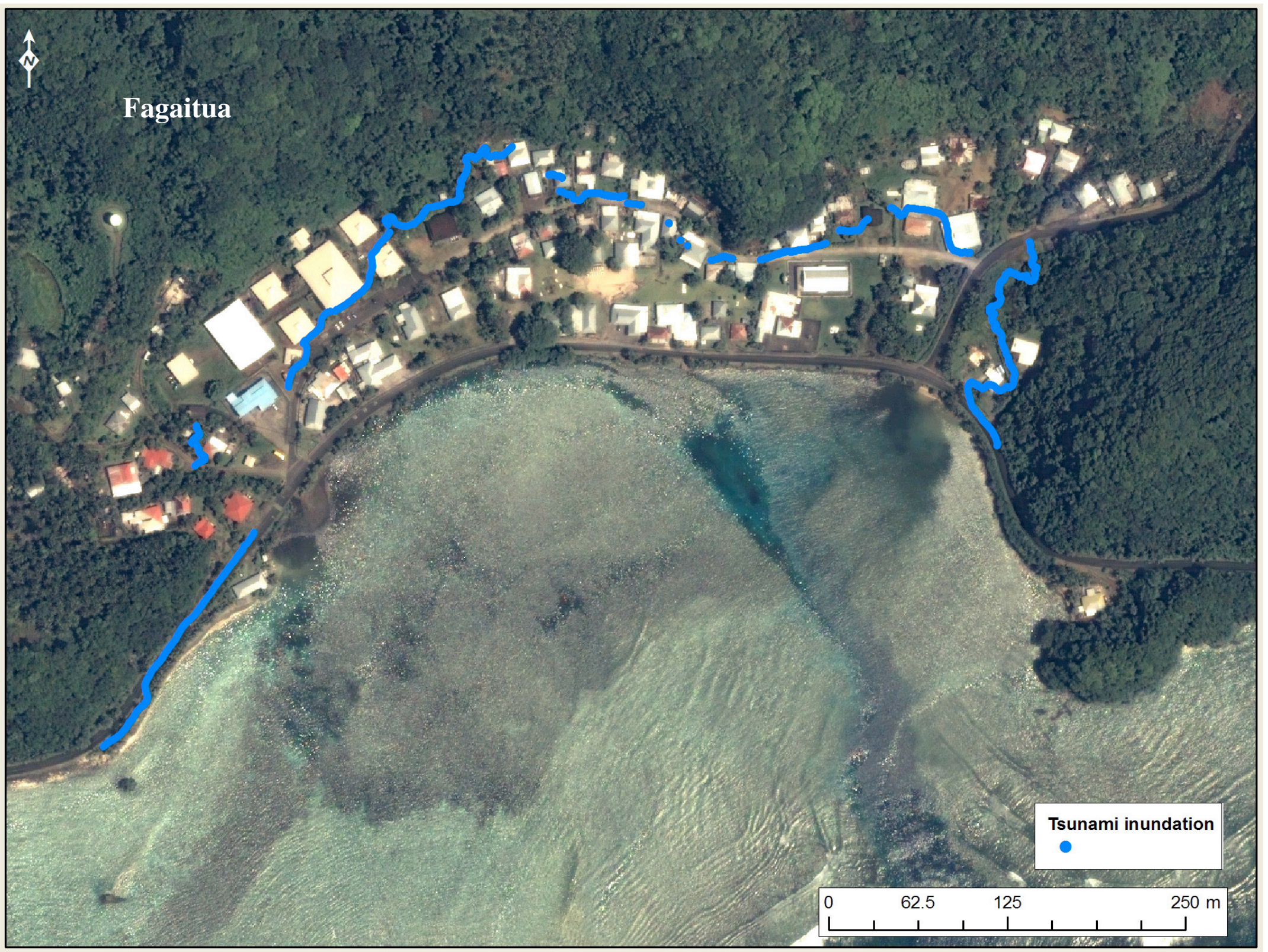

Figure A10. Limit of inundation of the September 29, 2009, tsunami at Fagaitua, American Samoa. DGPS error and location uncertainty are quantified in the electronic files accompanying this report. 


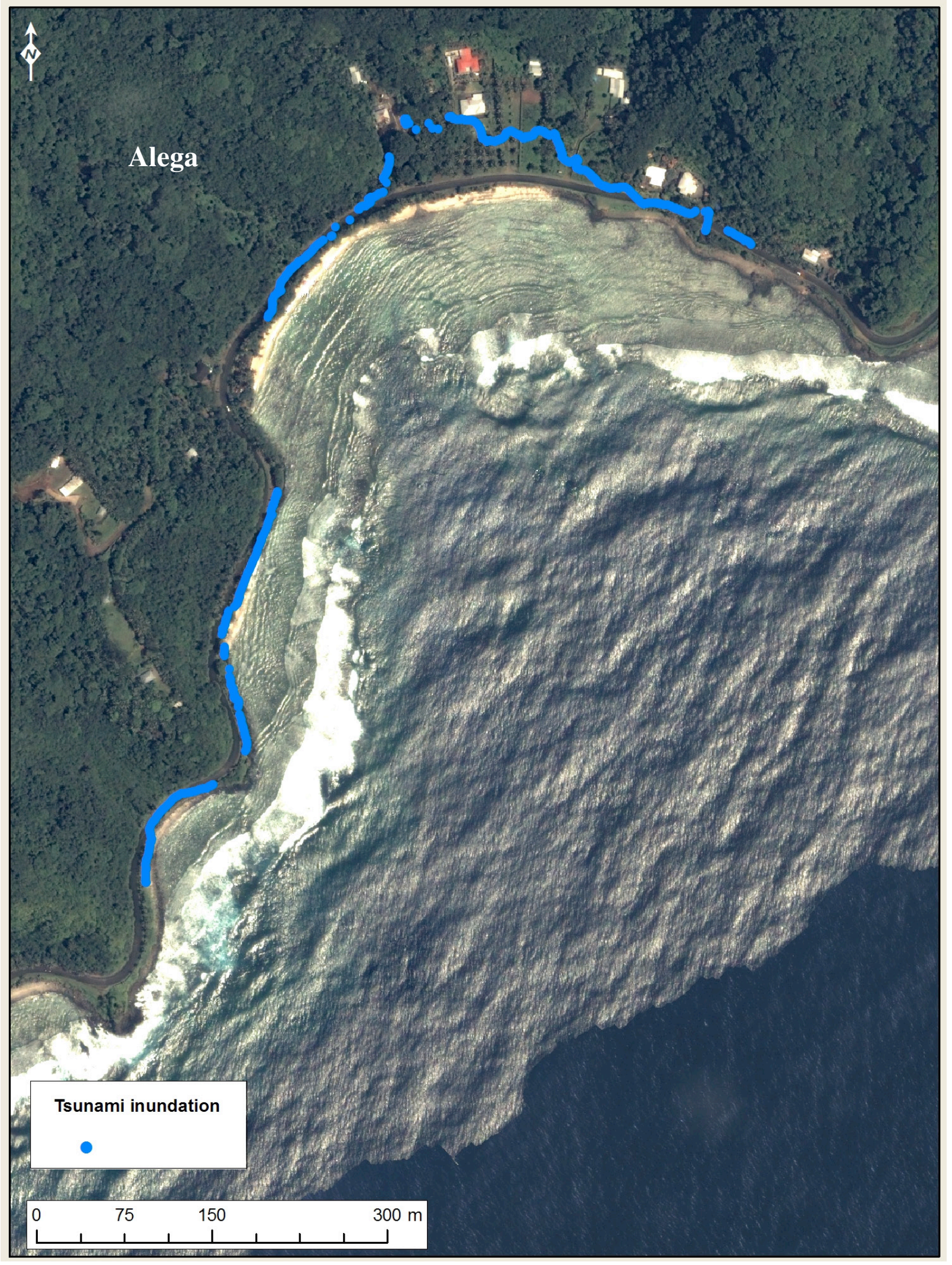

Figure A11. Limit of inundation of the September 29, 2009, tsunami at Alega, American Samoa. DGPS error and location uncertainty are quantified in the electronic files accompanying this report. 


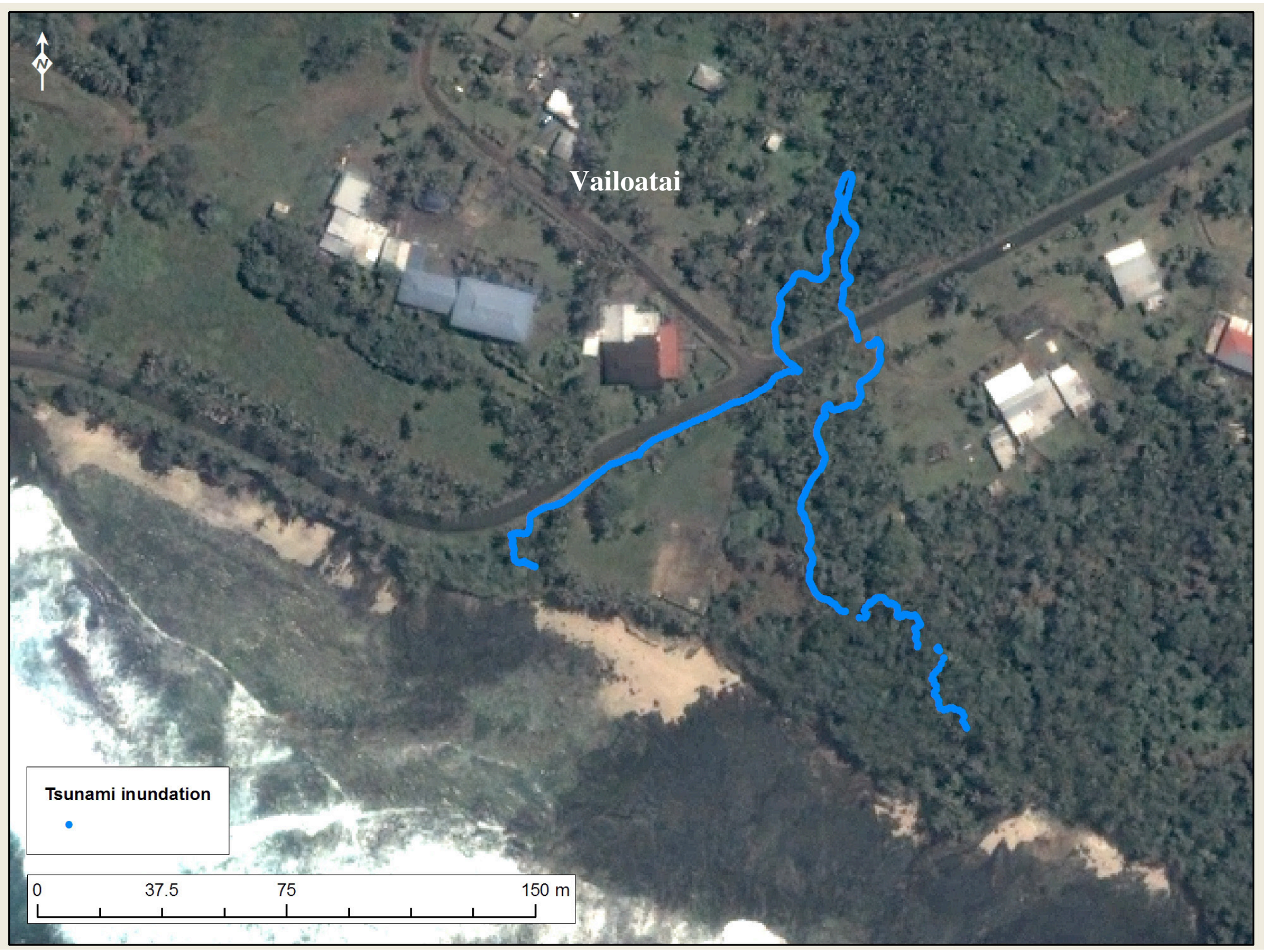

Figure A12. Limit inundation of the September 29, 2009, tsunami at Vailoatai, American Samoa. DGPS error and location uncertainty are quantified in the electronic files accompanying this report. 


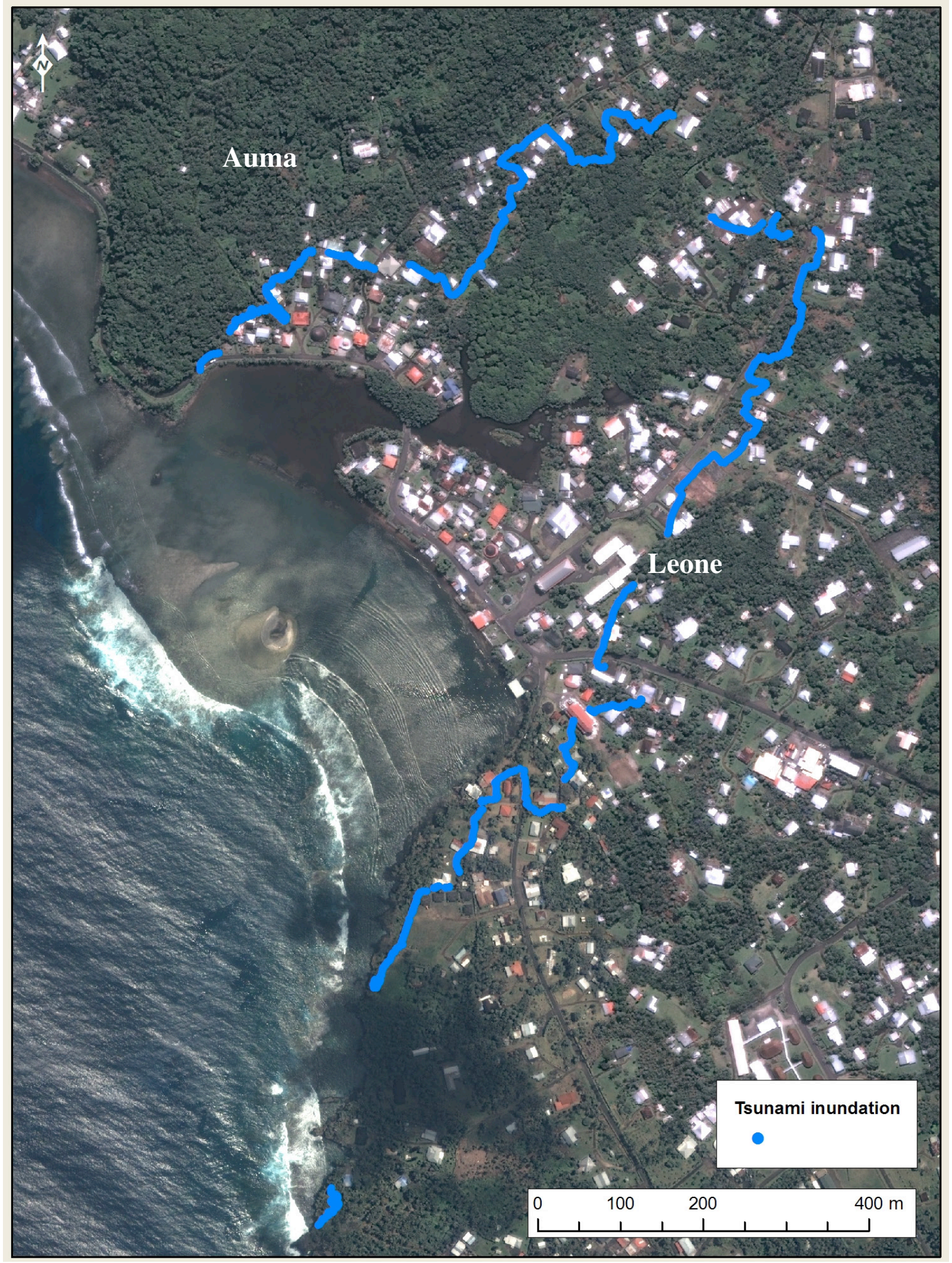

Figure A13. Limit of inundation of the September 29, 2009, tsunami at Auma and Leone, American Samoa. DGPS error and location uncertainty are included in the electronic files accompanying this report. 


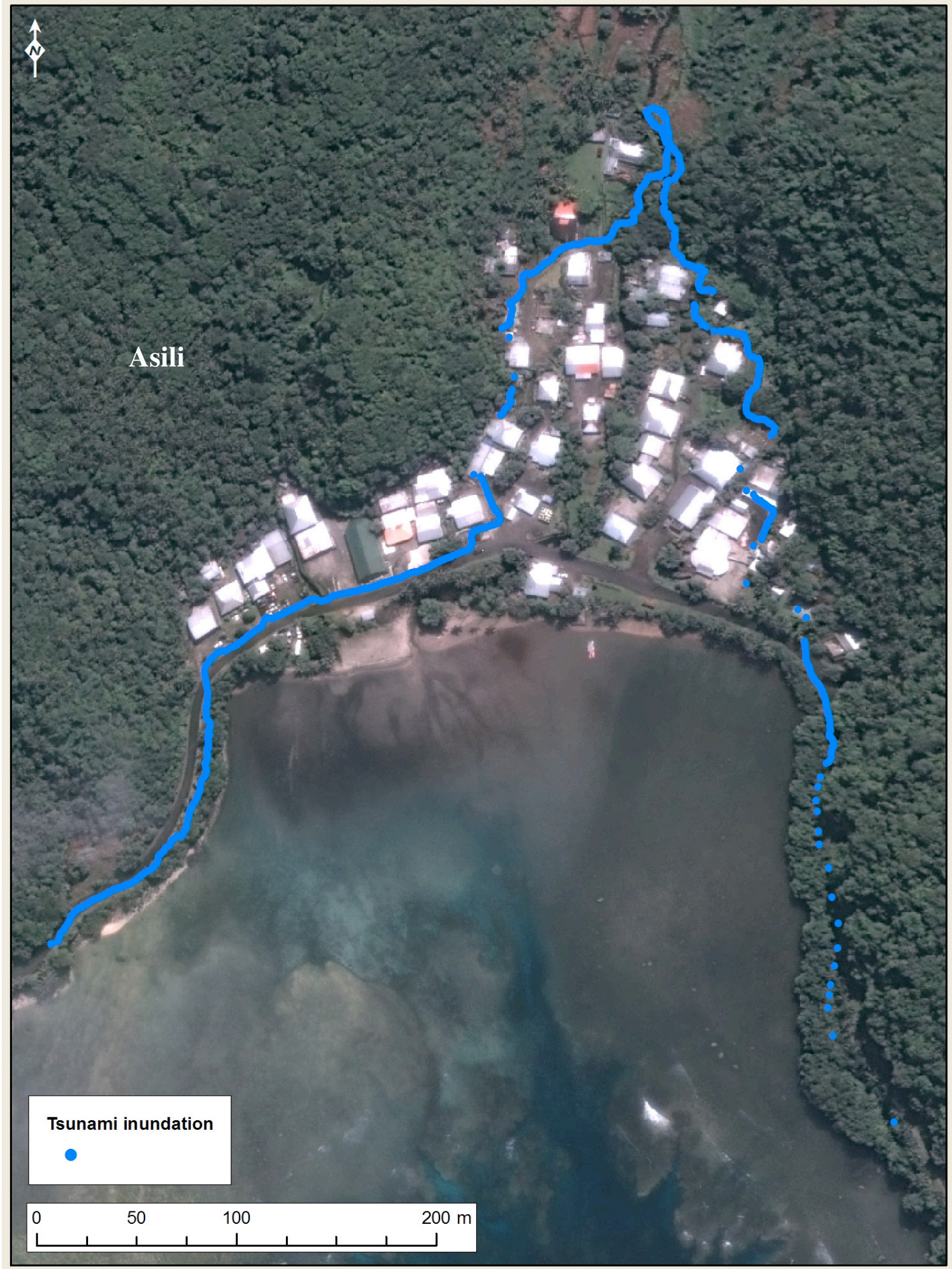

Figure A14. Limit of inundation of the September 29, 2009, tsunami at Asili, American Samoa. DGPS error and location uncertainty are included in the electronic files accompanying this report. 


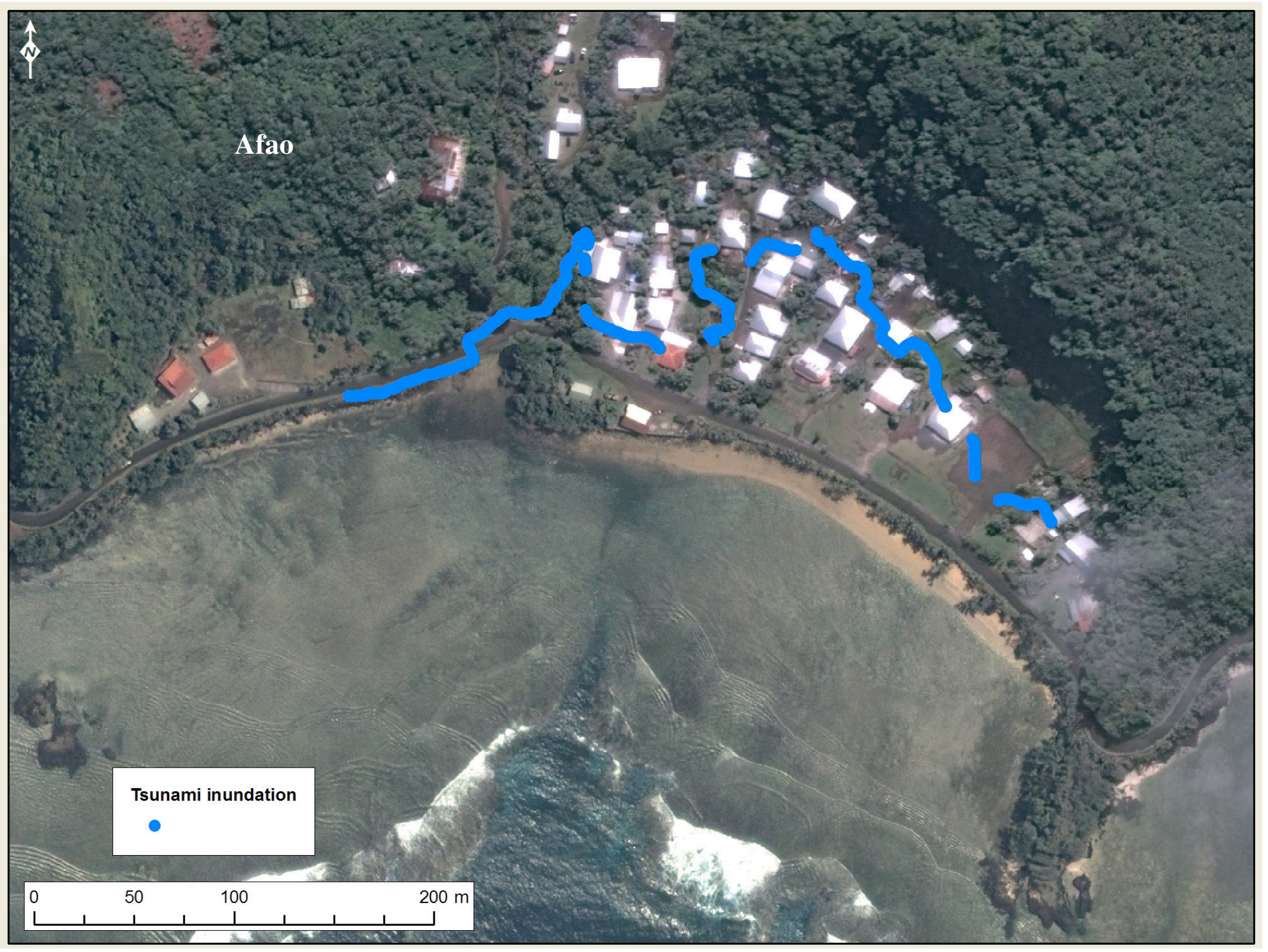

Figure A15. Limit of inundation of the September 29, 2009, tsunami at Afao, American Samoa. DGPS error and location uncertainty are quantified in the electronic files accompanying this report. 